\title{
Title:
}

\section{DIAGNOSTIC AND THERAPEUTIC CHALLENGES IN THE MANAGEMENT OF OBSTRUCTIVE DEFECATION}

\section{Authors:}

Esperanza Martos Vizcaíno, Constanza Ciriza de los Ríos, Fernando Canga Rodríguez-Valcárcel

DOI: $10.17235 /$ reed.2021.7587/2020

Link: PubMed (Epub ahead of print)

Please cite this article as:

Martos Vizcaíno Esperanza, Ciriza de los Ríos Constanza , Canga Rodríguez-Valcárcel Fernando. DIAGNOSTIC AND THERAPEUTIC CHALLENGES IN THE MANAGEMENT OF OBSTRUCTIVE DEFECATION. Rev Esp Enferm Dig 2021. doi: 10.17235/reed.2021.7587/2020.

This is a PDF file of an unedited manuscript that has been accepted for publication. As a service to our customers we are providing this early version of the manuscript. The manuscript will undergo copyediting, typesetting, and review of the resulting proof before it is published in its final form. Please note that during the production process errors may be discovered which could affect the content, and all legal disclaimers that apply to the journal pertain. 


\section{7587}

Diagnostic and therapeutic challenges in the management of obstructive defecation

Esperanza Martos Vizcaíno', Constanza Ciriza de los Ríos ${ }^{2}$ and Fernando Canga Rodríguez-Valcárcel ${ }^{3}$

${ }^{1}$ Department of Gastroenterology and Hepatology. Hospital Universitario Gregorio Marañón. Madrid, Spain. ${ }^{2}$ Department of Gastroenterology and Hepatology. Hospital Universitario Clínico San Carlos. Madrid, Spain. ${ }^{3}$ Departament of Gastroenterology and Hepatology. Hospital Universitario 12 de Octubre. Madrid, Spain

Correspondence: Esperanza Martos Vizcaíno

e-mail: emartosvizcaino@gmail.com

Conflict of interest: the authors declare no conflict of interest.

Keywords: Chronic constipation. Obstructive defecation. Solitary rectal ulcer. Highresolution anorectal manometry. Dyssynergic defecation.

Dear Editor,

Chronic constipation is a very common disease in daily clinical practice with a significant deterioration in quality of life that increases when associated with obstructive defecation. For this reason, we believe that the case presented here can improve our knowledge of these problems.

\section{Case report}

A 53-year-old female reported life-long constipation defined as difficulty to evacuate with excessive straining and sensation of incomplete evacuation. The rectal examination showed an incomplete opening of the anal canal with defecation maneuver and an anterior rectocele. Colonoscopy showed a 3-cm rectal ulcer, without specific signs, histological or microbiological analysis. 
High-resolution anorectal manometry (HRAM) with a 12-sensor solid-state catheter was performed with a mild hypotonic internal anal sphincter; type I dyssynergy pattern (Fig. 1A) and rectal hypersensitivity. The balloon expulsion test (BET) was expelled in 12 seconds (1). A fluoroscopic defecography was performed with an adequate rectumanal angle opening during straining, moderate anterior rectocele $(2.6 \mathrm{~cm})$ and enterocele grade III (Fig. 1B). The diagnosis was chronic constipation due to obstructive defecation and a secondary solitary rectal ulcer (SRU).

This case reflects the diagnostic doubts and the complex management of these patients, which must be addressed by a multidisciplinary team. HRAM showed type I dyssynergia (DD). However, the BET did not support this diagnosis. When there is a discrepancy between HRAM and BET, defecography is required. However, our patient only presented one of the three radiological criteria to define DD. The presence of SRU could also interfere in our results as these patients usually have hypersensitivity and paradoxical contraction of the puborectal during pushing (2).

Most guidelines currently assume that there is no gold standard for the diagnosis of DD and criteria must be met in at least two techniques. However, the current evidence shows a poor concordance (3).

Regarding treatment, these patients do not usually respond to conventional treatments for constipation. Sucralfate enemas demonstrated a remarkable improvement for the SRU (Fig. 1B) (4). The patient was treated initially with biofeedback (5) and pelvic floor rehabilitation. However, the important structural alterations may require surgical repair, with the aid of rehabilitative techniques that help to carry out an adequate defecation maneuver.

\section{References}

1. Mínguez $M$, Herreros $B$, Sanchiz $V$, et al. Predictive value of the balloon expulsion test for excluding the diagnosis of pelvic floor dyssynergia in constipation. Gastroenterology 2004;126(1):57-62. DOI: 10.1053/j.gastro.2003.10.044

2. Qing-Chao Zhu, Shen RR, Qin HL, et al. Solitary rectal ulcer syndrome: clinical features, pathophysiology, diagnosis and treatment strategies. World J Gastroenterol 2014;20(3):738-44. DOI: 10.3748/wjg.v20.i3.738 
3. Palit $\mathrm{S}$, Thin $\mathrm{N}$, Knowles $\mathrm{CH}$, et al. Diagnostic disagreement between tests of evacuatory function: a prospective study of 100 constipated patients. Neurogastroenterol Motil 2016;28:1589-98. DOI: 10.1111/nmo.12859

4. Somani SK, Ghosh A, Avasthi G, et al. Healing of a bleeding solitary rectal ulcer with multiple sessions of argon plasma. Gastrointest Endosc 2010;71:578-82. DOI: 10.1016/j.gie.2009.10.038

5. Jarrett $\mathrm{ME}$, Emmanuel $\mathrm{AV}$, Vaizey $\mathrm{CJ}$, et al. Behavioral therapy (biofeedback) for solitary rectal ulcer syndromes improves symptoms and mucosal blood flow. Gut 2004;53:368-79. DOI: 10.1136/gut.2003.025643 


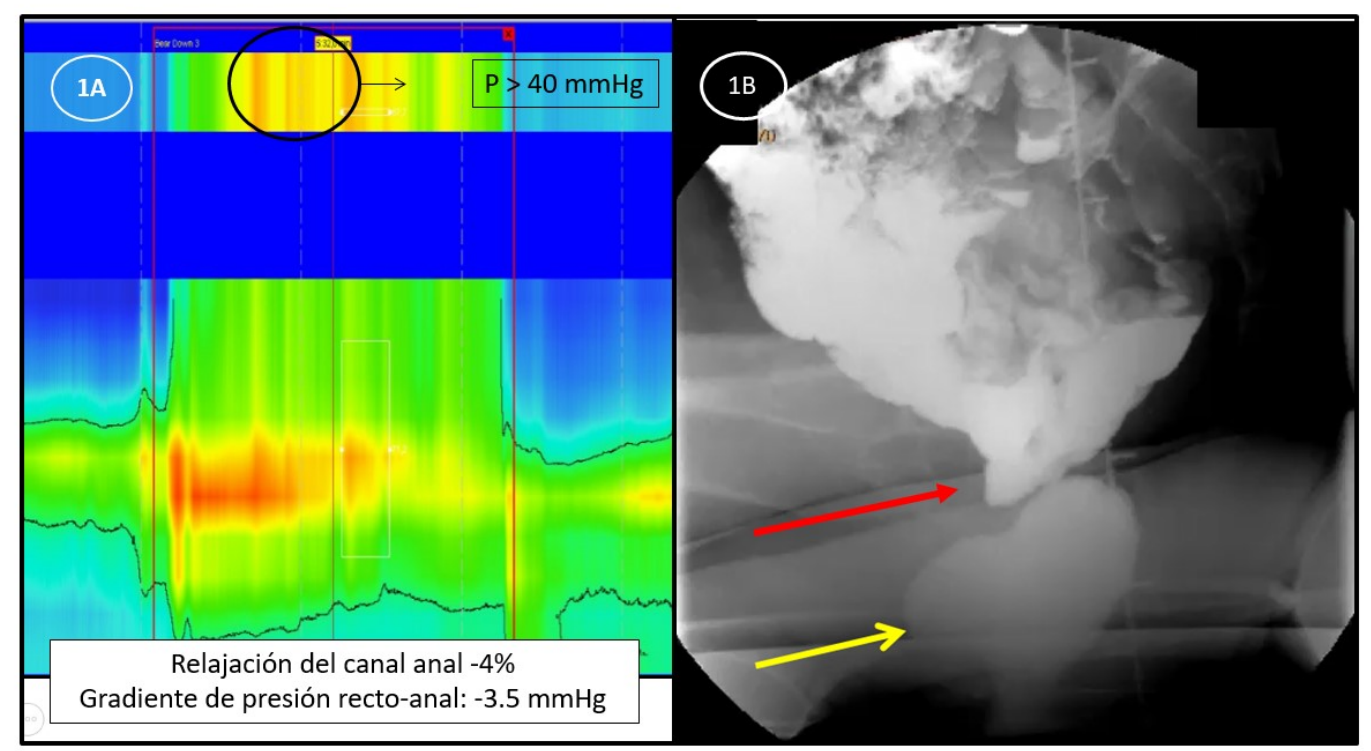

Fig. 1. A. Simulated evacuation without rectal distention with high-resolution anorectal manometry (HRAM). There is an adequate propulsive force ( $>40 \mathrm{mmHg}$ ) but there is an inadequate ( $\leq 20 \%$ ) relaxation of anal sphincter. B. Simulated defecation by defecography. An anterior rectocele of a moderate size (yellow arrow) and a severe enterocele (red arrow) were observed; the intestinal loops exceeded the coccyx line and remained situated anterior to the rectum. 